Kohlert, Frederik Byrn

Suggested citation:

Kohlert, Frederik Byrn (2015) Working it through: Trauma and autobiography in Phoebe Gloeckner's A Child's Life and The Diary of a Teenage Girl. South Central Review: The Journal of the South Central Modern Language Association, 32. p. 124. ISSN 1549-3377 Available at http://openresearch.ocadu.ca/id/eprint/1628/

(C) The Johns Hopkins University Press, Journals Publishing Division

Open Research is a publicly accessible, curated repository for the preservation and dissemination of scholarly and creative output of the OCAD University community. Material in Open Research is open access and made available via the consent of the author and/or rights holder on a non-exclusive basis.

The OCAD University Library is committed to accessibility as outlined in the Ontario Human Rights Code and the Accessibility for Ontarians with Disabilities Act (AODA) and is working to improve accessibility of the Open Research Repository collection. If you require an accessible version of a repository item contact us at repository@ocadu.ca. 


\title{
Working it Through: Trauma and Autobiography in Phoebe Gloeckner's A Child's Life and The Diary of a Teenage Girl
}

\author{
Frederik Byrn Køhlert, University of Calgary
}

In вотH the ALL-COMics Collection $A$ Child's Life and her innovative text/comics hybrid The Diary of a Teenage Girl, American cartoonist Phoebe Gloeckner mines the autobiographical material of her sexually traumatic childhood and early teens, and does so with a visual honesty that has often caused her work to be the subject of controversy. ${ }^{1}$ Strikingly and even confrontationally visual, and preoccupied with questions of truth and representation, Gloeckner's two books offer an opportunity to explore the relationship between autobiography, trauma and comics. Because of her blunt representations of teenage female sexuality, critical work on Gloeckner has largely focused on her use of the comics form to complicate and challenge the production of visual pleasure for the (male) reader, as well as on her depiction of female sexuality as consisting of an ambivalent combination of pleasure and degradation. ${ }^{2}$ But while critics such as Hillary Chute focus their analysis on the particular "ethical and troubling visual aesthetics" of Gloeckner's images and rightly point out that they are "consistently informed by trauma," no sustained attempts have so far been made to interpret her work formally in the context of trauma studies. ${ }^{3}$ In the following, I will therefore examine the resonance between comics formalism and theoretical work on trauma, and apply this discussion to a consideration of Gloeckner's work that demonstrates the close relationship between her aesthetic strategies and the visual nature of traumatic memories. More broadly, I argue that the formal properties of comics autobiography offer unique opportunities for the representation of the largely visual memories associated with trauma, and that the narrativizing potential of the form can be productively mobilized both for therapeutic purposes and as a means to assert agency for the victim of trauma.

Despite having drawn comics since childhood, Gloeckner has not been prolific as a comics artist, but has instead worked mainly as a commercial and medical illustrator. Her work has appeared sporadically in such magazines as Wimmen's Comix, Weirdo and Twisted Sisters, and most of it features her alter ego Minnie Goetze as a child and teenager in 1970s San Francisco. The Diary of a Teenage Girl, explicitly, is based on 
Gloeckner's own diary from when she was fifteen, with approximately half of it reproduced verbatim from the original. ${ }^{4}$ Perhaps surprisingly, in an age where autobiography is an established genre in mainstream literature and a seeming shortcut to respectability in the increasingly fashionable world of so-called "graphic novels" (the irony of the publishing industry term as used in relation to non-fiction comics notwithstanding), Gloeckner has often expressed reservations about her work being labeled as autobiographic. Where the work of artists such as Alison Bechdel, Marjane Satrapi and Art Spiegelman, among others, has achieved an unprecedented level of critical acclaim partly because, one suspects, it engages with their authors' real world of non-superheroes, Gloeckner has repeatedly insisted on the essential fictionality of her work. In the Diary, she pointedly includes in the front matter the disclaimer that "this account is entirely fictional and if you think you recognize any of the characters as an actual person, living or dead, you are mistaken." ${ }^{\text {In }}$ an interview with Whitney Joiner conducted at the time of the publication of the Diary, Gloeckner further explains: "By reading that book, you're not experiencing what I experienced. You're perhaps experiencing my interpretation of it, but you're bringing yourself to it. In that way, I always hesitate to say this is a true story. I'm not attempting in any way to make documentary. You can never represent everything. It's always a selective process." ${ }^{\circ}$ Despite these considerations, later in the interview Gloeckner interchangeably refers to herself and her character Minnie, who looks like her and is the protagonist of both books, and also acknowledges: "I mean, really, my motivation is, 'This all happened to me. I feel really totally fucked-up. I don't understand any of this. Let's look at it. Let's not look at it sideways or make it look prettier, but let's just look at it for what it is." "Aside from signaling Gloeckner's refusal to capitalize on the current vogue for autobiographical comics, this position reveals her unease with designating something as being "true," even if it really happened, and also aligns her with current theories of life narrative, which contest the truth/fictionality binary of all self-representation. ${ }^{8}$

But while Gloeckner acknowledges the use of her own life as the raw material for the book, she also stresses the need to reshape the diary in order to make it cohere as a narrative and arrive at a different kind of truth: "sometimes you have to distort 'reality' in order to express what you feel is the true feeling. A recounting of facts can carry little meaning. An artist imposes a certain order on perception." "In her study of the boundaries and limit-cases of contemporary autobiography, Leigh Gilmore similarly argues that "the autobiographical project may swerve from the form of autobiography even as it embraces the project of self-representation." 10 
Indeed, when compared to classic autobiography, which is a genre fraught with legalistic and juridical concerns, most modern theories of the form are working from a presumption of a contradictory and split subject, which asks the reader to "submit to a fiction" when "offered some kind of cohesion of the writing 'subject' which is guaranteed by the writing signature, by the name which is attached to the text." "This double fiction, which first presents an autobiographical narrative that is inescapably shaped by a subject that in turn is considered fragmented, incoherent and a product of discursive identity-formation, means that critics have often considered it "more helpful to approach autobiographical telling as a performative act." 12 Keeping in mind Judith Butler's influential notion that performativity "must be understood not as a singular or deliberate 'act,' but, rather, as the reiterative and citational practice by which discourse produces the effect that it names," the performance of the self in autobiography can thereby in important ways be constitutive of subjectivity, as the writer creates a unified representation of a largely fictional self from the available discursive resources. ${ }^{13}$ Autobiography, then, seems to offer what Gilmore has called "an opportunity for self-transformation" and, using the phrase of Charles Ruas, "a speculative project in "how to become other." 14 The idea of a fragmented, reiterative and citational practice through which the author can construct a sense of self through narrative, therefore, has clear implications for the opportunities offered by autobiography in the form of comics.

Comics is an inherently discontinuous form consisting of individual drawings arranged in panels on the page and separated by the blank spaces of the gutters. With a highly structured narrative that nevertheless literally functions through visual abstraction and fragmentation, the form seems fitting for the contemporary project of autobiography as outlined above. Furthermore, as Jared Gardner has argued regarding the supposed responsibility of autobiography to adhere to a version of the "truth":

The comics form necessarily and inevitably calls attention through its formal properties to its limitations as juridical evidence - to the compressions and gaps of its narrative (represented graphically by the gutterspace between the panels) and to the iconic distillations of its art. The kinds of truth claims that are fought over in the courts of law and public opinion with textbased autobiography are never exactly at issue in graphic autobiography. The losses and glosses of memory and subjectivity are foregrounded in graphic memoir in a way they never can be in traditional autobiography. ${ }^{15}$ 
To ask for autobiographical "truth" in comics is therefore to ask for something that is inimical to the form. Where in traditional prose autobiography the mimetic world of the work is constructed by the reader's imagination, which creates its own reality and can elect to presuppose a corresponding externality, the reality of the comics page is indubitably and self-evidently different from that which it represents. In this way impervious to truth claims, comics autobiography allows the artist to structure the narrative to correspond to a larger, emotional truth, and to visually externalize subjectivity on the page in a way that is constitutive of selfhood while remaining true to dominant ideas of the self as fragmented or multiple. The characteristics of the form itself can therefore be enabling for minorities whose subjectivity has been denied in that it offers a method to delineate and embody marginal selves, as well as a multiple perspective through which to resist the dominant interpellation by official society. That this approach has implications for feminist authors of autobiography such as Gloeckner is self-evident, but that the form is also a well-suited vehicle for the representation and working-through of trauma follows from many of the same observations.

According to Ruth Leys, the official designation of post-traumatic stress disorder by the American Psychiatric Association describes the ailment in terms of psychic fragmentation and the splitting of the subject:

The idea is that, owing to the emotions of terror and surprise caused by certain events, the mind is split or dissociated: it is unable to register the wound to the psyche because the ordinary mechanisms of awareness and cognition are destroyed. As a result, the victim is unable to recollect and integrate the hurtful experience in normal consciousness; instead she is haunted or possessed by intrusive traumatic memories. ${ }^{16}$

The split of the subject in the autobiographical project is thus mirrored in the psychic fragmentation caused by traumatic experience, the memories of which cannot be fitted easily into a life story because they create a gap within consciousness that defies narrativization and disrupts the formation of a coherent sense of self. The working through of traumatic events, therefore, requires the rescripting of the traumatic memories into an organizing narrative in a way that allows for the subject to assimilate the event itself into lived experience and eventually put it into the past. ${ }^{17}$ In addition to the integrative potential of narrative, great emphasis is placed on its externalization. "In the telling, the trauma story becomes a testimony," psychiatrist Judith Lewis Herman notes, and her point is 
echoed by Shoshana Felman who, according to Suzette A. Henke, argues that "a surrogate transferential process can take place through the scene of writing that allows its author to envisage a sympathetic audience and to imagine a public validation of his or her life testimony." ${ }^{18}$ Similarly, psychiatrist Dori Laub has ascribed significant importance to the role of the witness in the process of working through traumatic memories, either at "the level of being a witness to oneself within the experience [or at] the level of being a witness to the testimonies of others." ${ }^{19}$ The idea of the displacement and narrativization of trauma through externalizing testimony is as old as Freud's "talking cure," of course, and much theory concerning the literature of trauma mention a version of what Henke, among others, have called scriptotherapy, as the paradigm through which such texts work. ${ }^{20}$ Henke, drawing on Herman, argues that "the object of psychoanalysis - and of autobiography as scriptotherapy - is to 'reassemble an organized, detailed, verbal account, oriented in time and historical context' out of 'fragmented components of frozen imagery and sensation." ${ }^{21}$ While language in the form of narrative is in this way often theorized as crucial to the processing of trauma, whether in a therapeutic or literary context, Henke's comments also suggest the particular paradox of attempting to represent in words that which is often described as being inherently visual or sensory.

The notion that traumatic memories are predominantly visual in nature is supported by both biology and the vocabulary of visuality that is commonly utilized when describing trauma. According to Bessel A. van der Kolk and Onno van der Hart, "cognitive psychologists have identified three modes of information encoding in the CNS [central nervous system]: inactive, iconic and symbolic/linguistic." 22 Because trauma is commonly defined as "a frightening event outside of ordinary human experience," they argue, people exposed to traumatic events "experience a "speechless terror" that "cannot be organized on a linguistic level, and this failure to arrange the memory in words and symbols leaves it to be organized on a somatosensory or iconic level. ${ }^{.23}$ In addition to this neurobiological account, the difficulty of language to adequately represent trauma has appeared as something of a consensus among literary theorists working with trauma, and the nature of traumatic memories is usually described in mainly visual terms. ${ }^{24}$ To that effect, E. Ann Kaplan mentions "trauma's peculiar visuality as a psychic disorder," Leigh Gilmore argues that traumatic memory "expresses itself in flashbacks and fragments," and Suzette A. Henke, again following Herman, describes its "stereotyped, repetitious" quality and explains how its "iconic and visual" images "intrude on the consciousness as 'a series of snapshots 
or a silent movie." ${ }^{25}$ Language thus occupies a peculiar double role in the theorization of trauma, where it is asserted as the tool for creating an organizing narrative through the model of scriptotherapy at the same time that it is theorized as somehow unable to represent the particular visuality of traumatic memories. This conceptual paradox is at the heart of literary trauma studies, and theorists working with trauma have therefore been at pains to develop a framework in which the written word can be equal to the representational task at hand. ${ }^{26}$

But what if language itself was to be accompanied by the inclusion of images in representations of trauma? In addition to being concomitant with representing that which is visual to begin with, the visual arts have long been acknowledged to possess therapeutic potential. Regarding the specific limits of language, Herman has noted about the therapeutic process that "as the narrative closes in on the most unbearable moments, the patient finds it more and more difficult to use words. At times the patient may spontaneously switch to nonverbal modes of communication, such as drawing or painting. Given the 'iconic,' visual nature of traumatic memories, creating pictures may represent the most effective initial approach to these 'indelible images."' ${ }^{27}$ According to psychotherapists Barry M. Cohen and Anne Mills, further, the concept of isomorphism, which refers to "the similarity in structure between a person's internal state and its outward expression [...] allows clients to externalize deeply personal experiences or sensations through the strategies and styles in their art, conveyed by lines, shapes and colors. ${ }^{28}$ Moreover, they note, visual art is "the medium of choice [...] for externalizing [the patients'] perceptions and concerns and accessing material that has been visually encoded." 29 The therapeutic practice of art, therefore, can be used to dissociate traumatic experiences as the patient externalizes the visually encoded traumatic memory. And since traumatic memories are predominantly visual yet seem to depend on the establishment of narrative for their integration into lived experience, it stands to reason that visual autobiography in the form of comics could be suitable for representing and working through that which is perhaps unrepresentable by language alone.

By relying on a combination of fragmented verbal and visual codes that together create narrative, the medium of comics in this way seems especially appropriate for the therapeutic representation of traumatic memories. Theorized as stereotypical, iconic and repetitious, these intrusive visual memories can be externalized and narrativized on the comics page. In the context of trauma, it therefore seems possible to suggest that the aforementioned split of the subject — between the "I" that is writing and drawing the autobiography and the "I" of the mimetic world (that is, the 
actual drawing on the page) — can be a way to externalize and represent the split-off and traumatized memories, which cannot be integrated into the normal psyche. On the page, these representations can be arranged into narrative, and much in the same way that scriptotherapy works to disclose the trauma "in a format that promotes sequential organization of thoughts and narrative formation," so does the "sequential art" of comics produce narrative from still images through the process of what Scott McCloud-borrowing from gestalt psychology and using a term that has unmistakable implications for the working through of trauma- has called the "closure" within and between panels. ${ }^{30}$ Thierry Groensteen, in a more rigorously theoretical explication of essentially the same process, coins the neologism "arthrology" to describe the relationship between panels and the production of narrative. Groensteen distinguishes between "restrained arthrology" (the relationship between panels in sequence) and "general arthrology" (the relationship between panels in the comics network in its entirety), but common to both types is the construction of narrative from individual units of largely visual information. ${ }^{31}$ The frameworks of McCloud and Groensteen are meant to describe the process from the perspective of the reader, but the aforementioned split subject of comics creates a similar position for the autographer, who, as Gardner has pointed out, can be "both victim of the trauma and detached observer." ${ }^{2}$ By externalizing visually encoded material as sequential drawings, the comics form can thus both represent individual traumatic memories in a way that language alone cannot, and also serve as the vehicle for the construction of a visual narrative that can help the event be integrated into lived experience. In the following, therefore, I will examine selected work by Gloeckner in an attempt to demonstrate that comics is indeed a medium that is particularly well-equipped for autobiographies of trauma.

The collection A Child's Life (2000) consists of stories and illustrations created over a period of more than twenty years, with the majority concerning the early life of Gloeckner's alter ego Minnie Goetze. The seven stories making up the title sequence describe Minnie as a child of about ten, living with her younger sister, mother and stepfather. The stepfather, Pascal, is significantly older than Minnie's mother, who is portrayed as easily dominated and looks not much older than a teenager herself. From the beginning, it is clear that Pascal has an excessive temper that often turns violent, and it later appears that he has a sexual interest in Minnie. Although the impulse is never acted on, Pascal is drawn as an angry, leering and slightly creepy-looking man, with curled lips and narrow, hard eyes. Minnie, in turn, is drawn as an intense-looking child with large, dark eyes, and Gloeckner's representative drawing style adds 
realism to both the characters and their environments. The stories cover such material as Pascal losing his temper and hitting Minnie and her sister while driving, his attempts to talk the mother into an open marriage, and his inappropriate interest in whether Minnie's friends have begun to develop breasts.

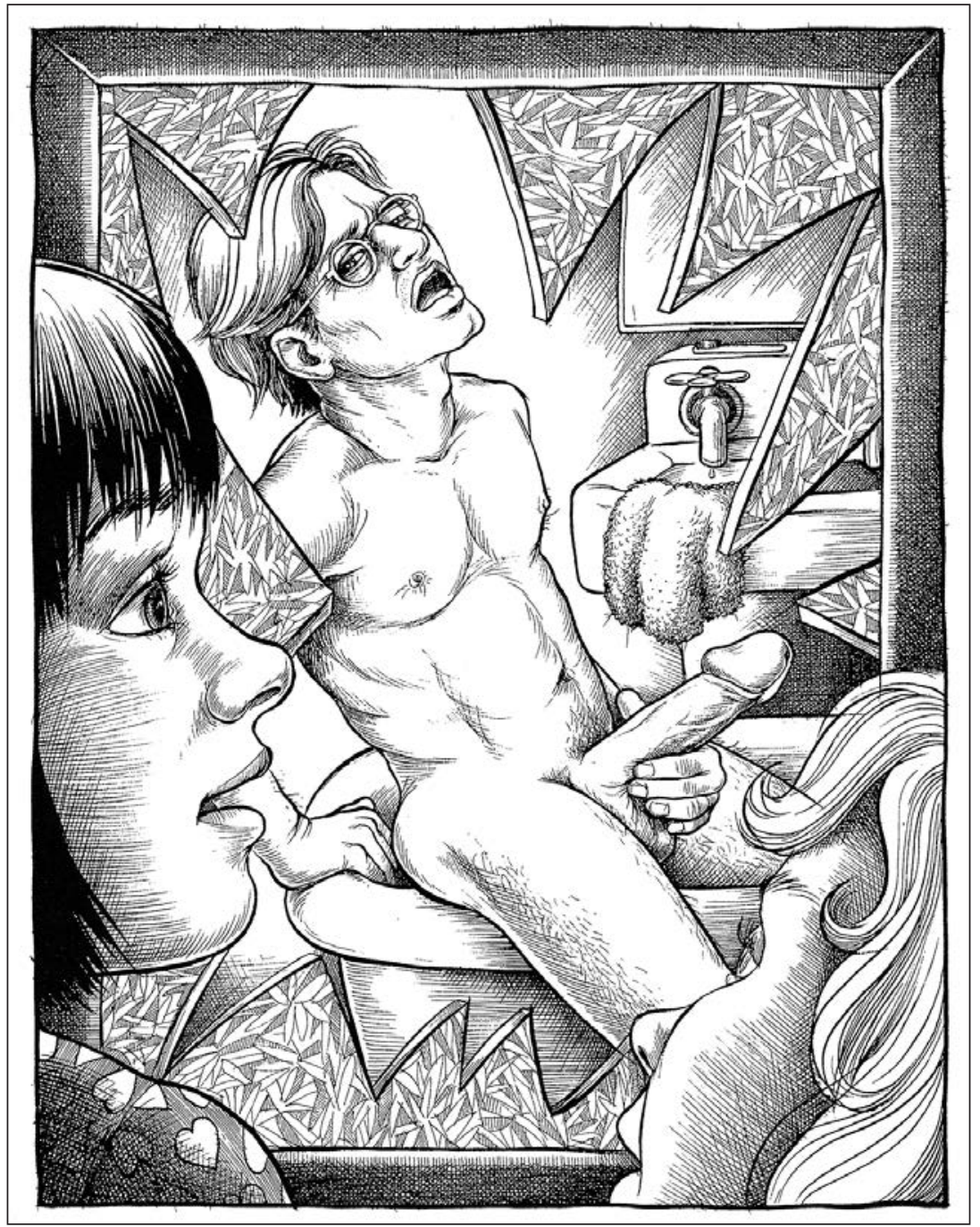

Figure I. From "Hommage à Duchamp." In Phoebe Gloeckner, A Child's Life and Other Stories, Berkeley: Frog, 2000, p. 28. 
In the course of the stories, one image in particular stands out in relation to the overall narrative. Taking up the entire second page of a threepage vignette entitled "Hommage [sic] à Duchamp," the image depicts Minnie and her sister discovering Pascal masturbating in the bathroom (figure 1). ${ }^{33} \mathrm{~A}$ pane of glass has been knocked out of the door, and the girls peer in through a frame that is bordered by broken glass. What they see is their naked stepfather, penis in hand and clearly close to orgasm, with his head turned slightly towards the girls but the direction of his gaze indeterminable. The image is constructed in three layers. The girls, the broken window and Pascal occupy three different planes, creating the identifying effect of standing behind the girls and looking into the bathroom with them. The sizes of Pascal's head and penis have been exaggerated greatly, suggesting their importance to the visual memory of the scene. The penis occupies the focus of attention by virtue, both, of the composition of the image and the direction of Minnie's gaze, which seems fixed upon it in a way that extends time and creates the effect of a lingering moment despite the swift and surprised feel of the scene. Minnie's right eye, which is the only one visible from the vantage point of the reader, is wide open in a way that also suggests the burning into visual memory of the scene. The size of the panel, further - taking up a full page - creates an effect both of shock, permanence and disruption of the narrative. When compared to its surrounding images, the panel has no visual indicators of time passing, such as motion lines or speech balloons, and the stillness adds to the effect of a moment frozen in time. The splintered glass, moreover, creates a jagged edge around the image, which both frames it and adds a symbolic layer that suggests the splintering of childhood and the sharp edges of adult consciousness. As Hillary Chute has perceptively pointed out about the image, "Minnie and her sister are both attracted and repulsed," and this ambivalence is clearly at the thematic center of the story, which concludes with the girls running away and trying to understand what they just witnessed. ${ }^{34}$ Serving as the centerpiece of the story, the image stands out and even interrupts the sequence for a variety of interrelated formal and thematic reasons, and in the context of an autobiographical story, therefore, it becomes clear that the image must occupy a prominent place in the author's childhood memories. Cathy Caruth has argued that "to be traumatized is precisely to be possessed by an image or event," and while the memory is perhaps not necessarily or overtly "traumatic" for the young Minnie, the drawing's design, size, and narrative placement nevertheless suggest the ability of the comics form to represent the kind of disruptive visuality commonly associated with traumatic memory. ${ }^{35}$ 

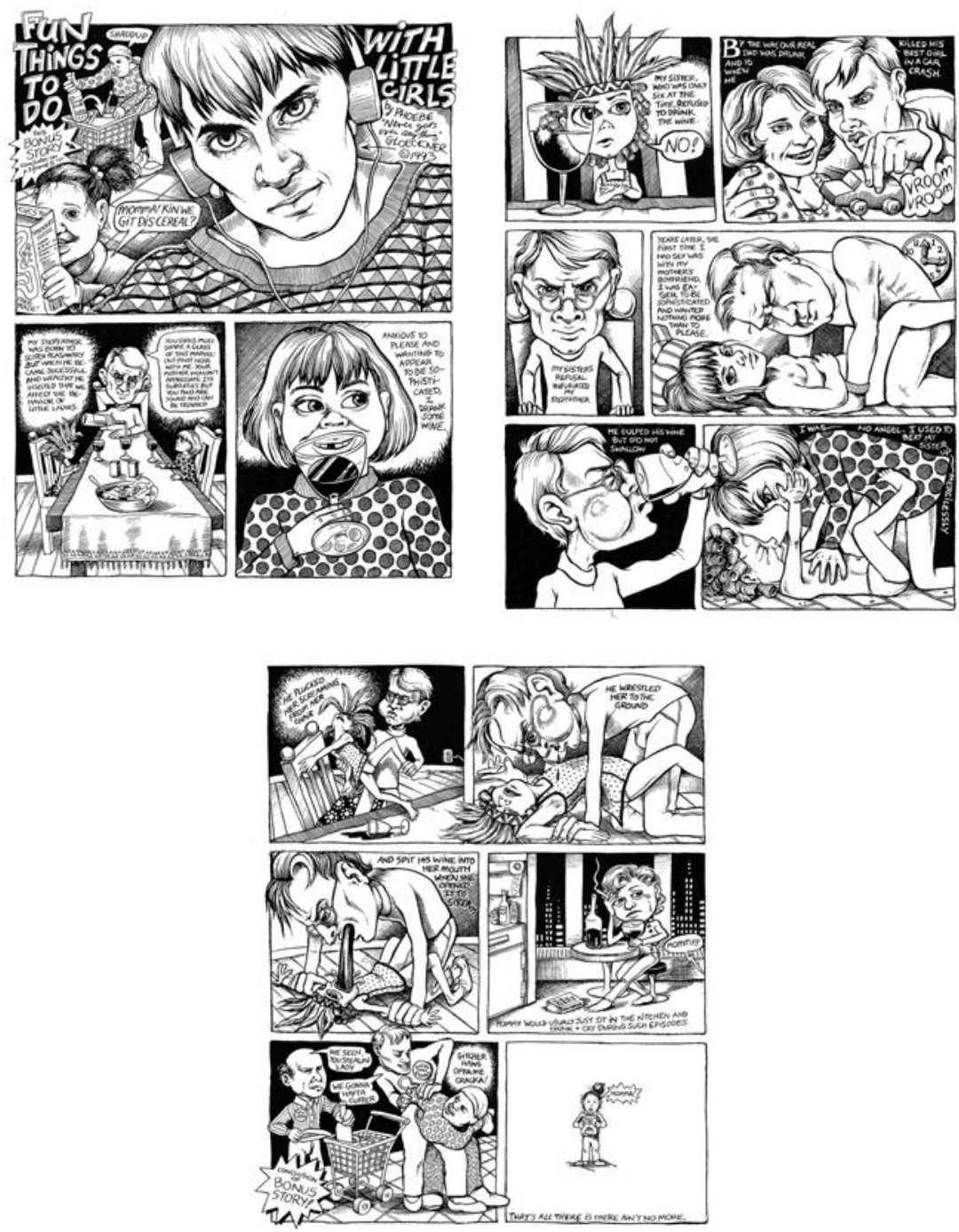

Figure 2. I-2.3. "Fun Things to Do with Little Girls." In Phoebe Gloeckner, A Child's Life and Other Stories, Berkeley: Frog, 2000, pp. 66-68.

Another story of childhood that functions by organizing experience according to the visual logic of the comics form, and does so in a way that explicitly suggests trauma in both form and content, is the specifically autobiographical "Fun Things to Do with Little Girls" (figures 2.1-2.3). Curiously placed in a section of the book that collects stories that are unrelated to the narrative about Minnie, the three-page story is credited 
to "Phoebe 'Never gets over anything' Gloeckner" and is told in the first person without the mention of any names. The characters are unmistakably the same as in the Minnie stories, however, both in appearance and characterization. The story depicts the Pascal character, now simply referred to as "my stepfather," trying to convince the two girls to try a glass of red wine. The Phoebe character, "anxious to please and wanting to appear sophisticated" drinks a little, while her younger sister, only six years old, refuses ${ }^{36}$ The main story now continues in the left-hand side of the relatively classic six-panels-per-page layout, and culminates as the stepfather fills his mouth with wine, holds the sister to the floor, and spits the wine into her mouth when she opens it to scream. The panel in which he holds the sister, wine dripping from his mouth, is placed on the right-hand side of the page, and is similar in pose to some of the other memories making up the rest of the interpolations into the narrative. The first of these is an image showing the Phoebe character having sex with her mother's boyfriend years later, the boyfriend hunched over her and dripping with sweat, while she looks indifferently towards the reader. This image also carries the narration that "years later, the first time I had sex was with my mother's boyfriend. I was eager to be sophisticated and wanted nothing more than to please. ${ }^{37}$ Making the connection between being encouraged to drink the wine and having sex with a man more than twice her age, the words underscore the immaturity of Phoebe's point of view, as well as the impression both events made on her. The next inserted memory is of a more general kind, but shows Phoebe fighting with her sister and pinning her to the floor in a pose reminiscent of both aforementioned images. Admitting that "I was no angel. I used to beat up my sister mercilessly," Gloeckner links her own aggressive behavior with both the violence of her stepfather and the sexual exploitation by her mother's boyfriend, and also suggests the potential for a causal relationship between the various manifestations of power. ${ }^{38}$ The relationship between these images illustrates Groensteen's notion of general arthrology, which describes how the visual resonances across the network of a comics page can create correspondences of meaning. Adding to and complicating the meaning of each individual panel as seen in isolation, what Groensteen refers to as the "braiding" of different images thereby explains how additional layers of narrative can appear outside of strict chronological progression. ${ }^{39}$

In Gloeckner's story, the last two of the images discussed above are inserted into the narrative before the event they are recalled by takes place, and the splintering thereby of linear temporal progression into fragmented space-time is resonant with the conceptualization of trauma 
as a visualization of repetitious frozen images brought to consciousness through flashbacks reminiscent of snapshots. Anne Whitehead has argued that "if trauma is at all susceptible to narrative formulation, then it requires a literary form which departs from conventional linear sequence," and the jumbled chronology creates the effect of both a gradual reveal and a compounding of the trauma, as one memory functions to uncover others. ${ }^{40}$ The effect of placing the similar images on the right-hand side of the page creates a fragmented yet sustained disruption of the narrative that signifies the split consciousness of trauma, wherein traumatic memories manifest themselves as intrusions into normal experience. The traumatic experience of seeing her sister violated in this way by her stepfather thus blurs into her visual memory of other events, to the point where she conceptualizes sexual violence and sibling infighting as manifestation of the same kind of transgression.

The two images appearing on the right side before and after the aforementioned three, in a sort of arthrological framing device, both have to do with alcohol. In the first of these, we learn that Phoebe and her sister's biological father was responsible for a car crash that "killed his best girl" when he "was drunk and 16," and in the final image of the story proper, we see the mother alone in the kitchen, where she would usually just "drink + cry during such episodes," without responding to a cry for "mommy!!" 41 The topos of alcohol further links these two events with the main narrative, and suggests that the wine acted as a catalyst for their remembrance. Finally, going one step up the associative ladder, a strange framing device depicts a story that seems to have triggered the whole traumatic series of memories. In addition to the intense stare of Gloeckner's adult face, the title panel depicts a woman in a supermarket putting a bottle of whiskey into her purse while her daughter asks for a package of cereal. With the reader informed that "this bonus story concludes on p. 3 frame 5," the woman is shown in the penultimate panel as being arrested for shoplifting, and in the last panel the daughter is depicted in an otherwise blank panel, looking scared and crying out "momma!"42 Linking both alcohol and its relationship with parental neglect to the main narrative, the frame story suggests that the traumatic memories were brought to the surface of the adult Gloeckner's consciousness when she observed this scene in a supermarket.

The final words of the story are written underneath the image of a scared little girl, and read "that's all there is there ain't no more," a reference to the last line of the many film and television adaptations of Ludwig Bemelmans's Madeline series of children's books. Ending the story with a line from children's entertainment underscores the childhood 
perspective on the events portrayed, at the same time that it emphasizes the sense of performativity and theatricality of the reconstructed narrative ${ }^{43}$ While Gloeckner somewhat humorously bills herself as unable to get over anything for this story, the mere creation of it and its extensive linking of traumatic memories from various points of her life indicates a certain distance to the memories, from where she is able to observe her life and work through the trauma by visually externalizing it on the page. The disorienting and splintered visual chronology typical of traumatic memories, moreover, is alleviated somewhat by the textual narration running through the story, which posits an organizing authorial subject who is both distinct from the visually represented events and in control of the narrative. The combination of text and image native to the comics form, therefore, allows for the construction of an integrative visualverbal narrative that is true to the nature of the traumatic memories while retaining the therapeutic potential of the narrativizing act. By virtue of the various layers of remembrance and memorialization, as well as the specific opportunities offered by the form, the story could arguably be considered to function as a sort of compulsive therapy, and Gloeckner continued to dramatize and work through many of the same events in The Diary of a Teenage Girl from 2002.

This book is presented as the written diary of fifteen-year-old Minnie Goetze, written over the course of a year when she was living with her mother and sister in San Francisco in the mid-1970s. The central story is repeated from a comic included in A Child's Life called "Minnie's $3^{\text {rd }}$ Love, or: Nightmare on Polk Street," and concerns Minnie's year-long sexual relationship with her mother's boyfriend Monroe, as well as her increasing drug-use and consequent love affair with a heroin-shooting prostitute named Tabatha. But while the material is depicted in an intensely graphic way in A Child's Life, The Diary of a Teenage Girl instead describes many of these events in words only. The most disturbing of the sequences, however, in which Tabatha gives Minnie some quaaludes and trades her unconscious body for drugs, is naturally presented in the $D i$ ary as a narrative absence - a blackout of which Minnie has no memory.

The text is based on Gloeckner's actual diary from this time, but while it was adapted and streamlined into a coherent story, the book is an adventurous formal construct. According to Whitehead, trauma narratives tend to include certain key stylistic features, including "intertextuality, repetition and a dispersed or fragmented narrative voice," all of which are present throughout the Diary. ${ }^{44}$ In addition to the written diary entries, the book includes a large number of illustrations of things, characters and scenes from the text, as well as several comics of varying length. 
The illustrations are of varied origin and, in addition to a large number of drawings made by Gloeckner as both a teenager and adult, include a drawing made by Gloeckner's father, who was a commercial artist, drawings by Aline Kominsky-Crumb and R. Crumb, with whom Gloeckner's mother socialized, and images taken from comics by Justin Green and Diane Noomin, among others. The comics fall into two categories: those drawn by Minnie/Phoebe at the time of the diary's composition, and a much larger number which were created by the adult Gloeckner at the time of the (re)writing of the book. The text itself is also multimodal, and includes letters from Pascal, at this point divorced from Minnie's mother, as well as dialogues representing conversations between Minnie and others, transcriptions of self-help tapes, lists, poems and song lyrics, in addition to the diary entries themselves. Changes in register are represented through differing font sizes, indentation and italics, all of which add to the amount of information communicated visually on the page. The multimodality made operational by the book's various strategies of representation suggests the fragmentation of the autobiographical subject, and also serves to foreground its complexity as a subjective construct. The plurality of perspectives, moreover, including the use of Gloeckner's own diary as the raw material from which the narrative is shaped, creates an intricate structure containing different perspectives on the same events while definitively ungrounding the idea of a single, coherent subject as the author of the autobiography.

In the book, the text is a mix of actual diaries written by the fifteenyear-old Gloeckner and additions and edits made by her adult self twentyfive years later. The comics created contemporaneously with the diary do not advance the story but serve as allegorical interludes, while the comics made by the adult Gloeckner portray events omitted in the diary from an adult perspective. The illustrations, likewise, are adult glosses on events described by a teenager (whether from the original diary or made by Gloeckner's adult author self). The outside perspective provided by the new comics and their realistic, almost documentary-like style, along with most of the illustrations, function as a commentary in which the adult author makes the teenage protagonist visible in an act of autobiographical remembrance and creation that allows for the internalized subjectivity of the author to become embodied on the page. Interspersed into the narrative, the comics and illustrations suggest that some memories are more visual than others, and can best be presented as such. This hybrid narrative form, containing multiple perspectives on Minnie's life, also represents her confusion and ambivalence as she knowingly enters into the sexual relationship with Monroe all the while refusing to be seen as 
a victim. Significantly, Minnie is as active in pursuing Monroe as he is in seducing her, and she exhibits a considerable sexual appetite throughout the narrative, insisting in her diary that "I really like getting fucked." And while the sexually experienced and often mature-sounding internal voice of the diary can sometimes obscure Minnie's age by turning her into a disembodied narrator, the images depicting a fifteen-year-old girl in bed with a much older man serve as a reminder of the essential inequality that is at the basis of the relationship, and which makes it morally — as well as legally - suspect (figure 3). The formal multimodality of the narrative in this way accentuates the thematic conflict between Minnie's feelings of being in control of her sexuality and the fact that she is an adolescent only a few years out of childhood. The diary entries themselves, by virtue of being from the point of view of a teenager somewhat excitedly caught up in events, lack the perspective brought to the book by the drawings made by the adult Gloeckner. Aware of the trauma, and of the effect it has had on her life since, Gloeckner offers the illustrations as a corrective to the first-person narrative's relative innocence, while remaining true to the authentic experience of her teenage self. The Diary thereby employs its pictorial elements to subtly show what the text itself is unable to tell, suggesting the full extent of the trauma only through implication and multimodal juxtaposition.

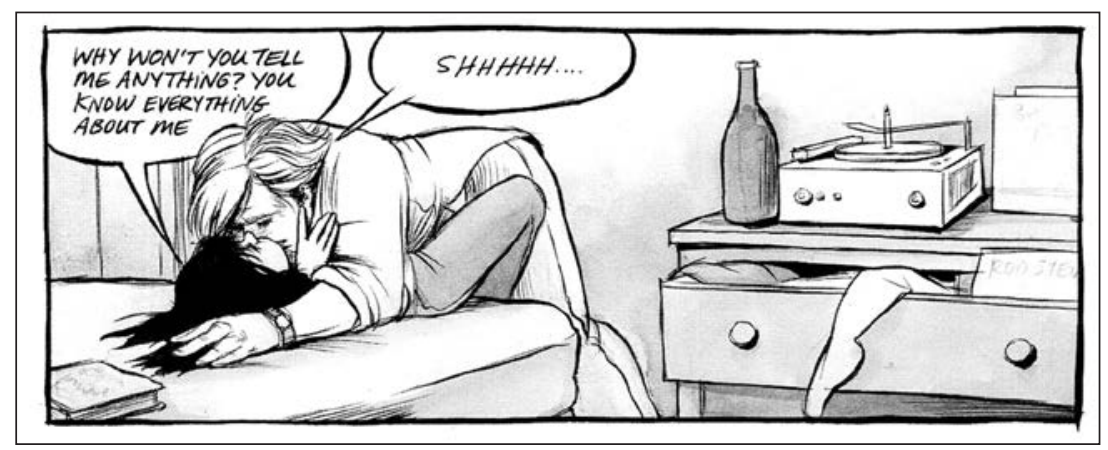

Figure 3. From Phoebe Gloeckner, The Diary of a Teenage Girl, Berkeley: Frog, 2002, p. 49.

The images in The Diary of a Teenage Girl bear witness to a case of sexual abuse in a way that the words alone do not. According to Kaplan, victims of traumatic situations "put their experiences in writing [...] for several reasons: to organize pain into a narrative that gives it shape for the purposes of self-understanding (working their trauma through), or 
with the aim of being heard, that is, constructing a witness where there was none before." ${ }^{46}$ With the Diary, Gloeckner has created a narrative from text left for her by her younger self, and the book can therefore be considered as a kind of therapeutic maneuver as the traumatic past has been sifted through, organized and made to cohere by the subjectivity of its adult author. In the process, the trauma is externalized onto the page through the visual objectification of the younger self, and a witness has been constructed in the reader. The visuality of the comics page, crucially, constructs both author and reader as literal eyewitnesses to the trauma, and while $A$ Child's Life and The Diary of a Teenage Girl use images in somewhat different ways, both works employ visuals in order to enunciate a state of subjective consciousness and restore a sense of agency to the traumatized self. By visualizing examples of hidden but all-too-common sexual abuse, Gloeckner reminds us that masculine control extends past mere visual representation in the public sphere and into the domain of private and interior lives, where such events are often silenced and denied by both aggressor and victim. The form, moreover, offers a way of creating closure between the fragmented images constituting both trauma and its own visual grammar, and the establishment of narrative from frozen images and stereotyped repetitions can thereby perhaps be healing as it is used to externalize and work through the traumatic event, as well as to contain it within the compartmentalized and clearly-defined panels of the comics page.

In both the political act of representation and her use of the form itself to depict and work through scenes of personal trauma, Gloeckner's two books not only make a case for the form's ability to represent traumatic memory and potentially serve as a therapeutic tool, but also illustrate the problem of adequately representing a self that is both fragmented and under duress. Where traditional autobiography aims to present the reader with a stable representation of a coherent subject, for Gloeckner the autobiographical project is an ongoing task bound up with repetition and a continual return to key events. Drawing on Caruth, Bina Toledo Freiwald argues about this tendency in general that "as a practice that allows a plural present self to grapple with its past(s), serial autobiography is both a symptom of and an antidote to the rupture that is trauma's aftermath - that 'breach in the mind's experience of time, self, and the world. " 47 Caruth herself notes that the "wound of the mind" created by trauma "is experienced too soon, too unexpectedly, to be fully known," and as Gloeckner continues to (re)write her story through an increasing number of panels, stories, and ultimately books, it is evident both that her use of the comics form is highly indebted to the experience and rhetoric 
of trauma and that its specific formal features provides her with a unique set of tools with which to attempt the ongoing and always incomplete task of representing a traumatized subjectivity as it exists in the breach between the known and the unknown. ${ }^{48}$

\section{NOTES}

1. The two most notable cases of Gloeckner's work causing controversy is the confiscation, in 2000, of $A$ Child's Life at the French border, as well as its ban from the Public Library System of Stockton, California, where it was deemed a "how-to" manual for pedophiles.

2. See J. Andrew Deman, “The Intervening 'I': Phoebe Gloeckner's Comics Memoir and the Destruction of Visual Pleasure," in American Visual Memoirs After the 1970s: Studies on Gender, Sexuality, and Visibility in the Post-Civil Rights Age, ed. Mihaela Precup (Bucharest: University of Bucharest Press, 2010); Meisha Rosenberg, "Multimodality in Phoebe Gloeckner's Diary of a Teenage Girl," International Journal of Comic Art 9.2 (2007); Hillary Chute, Graphic Women: Life Narrative and Contemporary Comics (New York: Columbia University Press, 2010).

3. Chute, Graphic Women, 91, 61.

4. Gloeckner discusses the source and particular textual arrangement of the Diary in Nathalie Atkinson, "My Not-So-Secret Identity: The Fact and Fiction of Phoebe Gloeckner," Broken Pencil 22 (2003): 18.

5. Phoebe Gloeckner, The Diary of a Teenage Girl (Berkeley: Frog, 2002), iv.

6. Whitney Joiner, "Not Your Mother's Comic Book," Salon.com (March 15, 2003).

7. Ibid. Perhaps surprisingly, given the ambivalence suggested by these statements, the cover of The Diary of a Teenage Girl features a photograph of a teenage Gloeckner, identified in the list of illustrations as "The real Minnie Goetze" (xiii).

8. While Gloeckner has consistently resisted labeling her work as autobiography, it is, as Chute has pointed out, "clearly self-representational," and I follow her in treating it as such here. See Chute, Graphic Women, 66.

9. Gary Groth, "Interview: Phoebe Gloeckner," The Comics Journal 261 (2004): 92. Similarly, Gloeckner has insisted elsewhere that "this is not history or documentary or a confession, and memories will be altered or sacrificed, for factual truth has little significance in the pursuit of emotional truth." Gloeckner, "Autobiography: The Process Negates the Term," in Graphic Subjects: Critical Essays on Autobiography and Graphic Novels, ed. Michael A. Chaney (Madison: University of Wisconsin Press, 2011), 179.

10. Leigh Gilmore, The Limits of Autobiography: Trauma and Testimony (Ithaca: Cornell University Press, 2002), 3.

11. Paul Smith, Discerning the Subject (Minneapolis: University of Minnesota Press, 1988), 104.

12. Sidonie Smith and Julia Watson, Reading Autobiography: A Guide for Interpreting Life Narratives (Minneapolis: University of Minnesota Press, 2001), 47.

13. Judith Butler, Bodies That Matter: On the Discursive Limits of "Sex" (New York: Routledge, 1993), 2.

14. Gilmore, Limits of Autobiography, 11.

15. Jared Gardner, “Autography's Biography, 1972-2007,” Biography 31.1 (2008): 6.

16. Ruth Leys, Trauma: A Genealogy (Chicago: University of Chicago Press, 2000), 2. 
17. To this effect, psychiatrists Bessel A. van der Kolk and Onno van der Hart have observed that "traumatic memories are the unassimilated scraps of overwhelming experiences, which need to be integrated with existing mental schemes, and be transformed into narrative language," and Judith Lewis Herman argues that the "work of reconstruction actually transforms the traumatic memory, so that it can be integrated into the survivor's life story." See Bessel A. van der Kolk and Onno van der Hart, "The Intrusive Past: The Flexibility of Memory and the Engraving of Trauma," in Trauma: Explorations in Memory, ed. Cathy Caruth (Baltimore: Johns Hopkins University Press, 1995), 176; Judith Lewis Herman, Trauma and Recovery (New York: Basic Books, 1997), 175.

18. Herman, Trauma and Recovery, 181; Suzette A. Henke, Shattered Subjects: Trauma and Testimony in Women's Life Writing (New York: St. Martin's Press, 2000), xii.

19. Dori Laub, "Truth and Testimony: The Process and the Struggle," in Caruth, Trauma: Explorations in Memory, 61.

20. Freud introduced the idea of the talking cure in Studies in Hysteria, his 1893 volume written with Josef Breuer. Using the term "abreaction," Breuer and Freud observed that "the injured person's reaction to the trauma only exercises a completely 'cathartic' effect if it is an adequate reaction - as, for instance, revenge. But language serves as a substitute for action; by its help, an effect can be 'abreacted' almost as effectively." See Josef Breuer and Sigmund Freud, Studies on Hysteria (New York: Basic Books, 1957), 8 . The term "scriptotherapy" has an unclear genealogy, but is in literary studies mainly associated with Henke, who defines it as "the process of writing out and writing through traumatic experience in the mode of therapeutic reenactment." See Henke, Shattered Subjects, xii. For authoritative overviews of the scientific literature on scriptotherapy, see Richard J. Riordan, "Scriptotherapy: Therapeutic Writing as a Counseling Adjunct," Journal of Counseling \& Development 74 (1996); and Joshua M. Smyth and Melanie A. Greenberg, "Scriptotherapy: The Effects of Writing About Traumatic Events," in Psychodynamic Perspectives on Sickness and Health, ed. Paul Raphael Duberstein and Joseph M. Masling (Washington, DC: American Psychological Association, 2000).

21. Henke, Shattered Subjects, xviii.

22. van der Kolk and van der Hart, "Intrusive Past," 172.

23. Ibid.

24. Regarding the difficulty of representing traumatic memories linguistically, see Gilmore, Limits of Autobiography, 6-7.

25. E. Ann Kaplan, Trauma Culture: The Politics of Terror and Loss in Media and Literature (New Brunswick, NJ: Rutgers University Press, 2005), 13; Gilmore, Limits of Autobiography, 29; Henke, Shattered Subjects, xvii-xviii.

26. Cathy Caruth, for example, insists that trauma must "be spoken in a language that is always somehow literary: a language that defies, even as it claims, our understanding," and Anne Whitehead notes that "the impact of trauma can only adequately be represented by mimicking its forms and symptoms, so that temporality and chronology collapse, and narratives are characterized by repetition and indirection." See Caruth, Unclaimed Experience: Trauma, Narrative, and History (Baltimore: Johns Hopkins University Press, 1996), 5; Anne Whitehead, Trauma Fiction (Edinburgh: Edinburgh University Press, 2004), 3.

27. Herman, Trauma and Recovery, 177.

28. Barry M. Cohen and Anne Mills, "Skin/Paper/Bark: Body Image, Trauma and the Diagnostic Drawing Series," in Splintered Reflections: Images of the Body in Trauma, ed. Jean Goodwin and Reina Attias (New York: Basic Books, 1999), 203. 
29. Ibid., 218.

30. Smyth and Greenberg, "Scriptotherapy," 139; Will Eisner, Comics and Sequential Art (New York: W. W. Norton, 2008); Scott McCloud, Understanding Comics: The Invisible Art (New York: Harper, 1994), 60-93.

31. Groensteen develops and uses this terminology throughout his book The System of Comics. See Thierry Groensteen, The System of Comics (Jackson: University of Mississippi Press, 2007).

32. Gardner, "Autography's Biography," 12.

33. For a reading of the image that connects it to Duchamp's famous installation Étant Donnés, on which it is clearly based, see Chute, Graphic Women, 71-72.

34. Ibid., 72.

35. Cathy Caruth, "Introduction," in Trauma: Explorations in Memory, 4-5.

36. Phoebe Gloeckner, A Child's Life and Other Stories (Berkeley: Frog, 2000), 66.

37. Ibid., 67.

38. Ibid.

39. Groensteen, System of Comics, 145-47.

40. In this formulation, Whitehead is explicitly drawing on Caruth. See Whitehead, Trauma Fiction, 6.

41. Gloeckner, Child's Life, 67, 68.

42. Ibid., 66 .

43. Ibid., 68 .

44. Whitehead, Trauma Fiction, 84.

45. Gloeckner, Diary, 26.

46. Kaplan, Trauma Culture, 20.

47. Bina Toledo Freiwald, "Social Trauma and Serial Autobiography: Healing and Beyond," in Unfitting Stories: Narrative Approaches to Disease, Disability, and Trauma, ed. Valerie Raoul, et al. (Waterloo, ON: Wilfrid Laurier University Press, 2007), 234.

48. Caruth, Unclaimed Experience, 3. 


\section{Notes on Contributors}

JIM COBY is an English Ph.D student at the University of Louisiana at Lafayette. His research focuses on Southern identities in twentieth-century literature, particularly how sense of self is altered by traumatic experiences. He has presented at numerous conferences on subjects ranging from the music of the Drive-By Truckers to the Mardi Gras Indians.

K.W. EVELETH is a Ph.D candidate at the University of Kentucky, specializing in transmedial narratology, graphic narrative, and children's literature. He has published works focusing on Kel Gilligan's Daredevil Stuntshow, the Scott Pilgrim transmedial series, and on participation in genre-bending indie games such as Braid.

ROBERT HUTTON is a Ph.D student in English at Carleton University, focusing on American literature and visual culture. He has previously been published in TOPIA (issue 33, Fall/Winter 2014), and presented at the conferences of the Northeast Popular Culture Association (2013) and the Society for Comparative Literature (2014).

FREDERIK BYRN KØHLERT is a postdoctoral fellow at the University of Calgary. He is the author of The Chicago Literary Experience: Writing the City, 1893-1953 (University of Copenhagen: Museum Tusculanum Press, 2011); "Female Grotesques: Carnivalesque Subversion in the Comics of Julie Doucet" in the Journal of Graphic Novels and Comics 3.1 (2012): 19-38; and "In the Ghetto: Sociology, the Cagney Gangster, and the 'Dead End' Kids in Angels with Dirty Faces" in the Journal of Popular Culture 47.4 (2014): 857-876.

ANDREW J. KUNKA is Professor of English at the University of South Carolina Sumter. He has published essays on Will Eisner, Jack Katz, Kyle Baker, Gene Luen Yang, and racial caricatures. He is currently working on a book about autobiographical comics for Bloomsbury's Comics Studies series (2016).

SINÉAD MOYNIHAN is a Senior Lecturer in Twentieth-Century Literature at the University of Exeter with research interests clustering around American, Irish and Transatlantic Literature and Culture, particularly in relation to questions of race, migration, displacement and diaspora. Her first book, Passing into the Present: Contemporary American Fiction of Racial and Gender Passing, was published by Manchester University Press in 2010. Her second, "Other People's Diasporas": Negotiating Race in Contemporary Irish and Irish-American Culture, appeared with Syracuse University Press in 2013.

NANCY PEDRI is Associate Professor of English at Memorial University of Newfoundland. Her major fields of research include word-and-image relations in contemporary literature, photography in fiction and comics studies. She has edited 4 volumes on word-and-image studies. Her work on word and image relations has appeared 
Reproduced with permission of the copyright owner. Further reproduction prohibited without permission. 